\title{
Felippe, Guilherme Galhegos A cosmologia construída de fora: a relação com o outro como forma de produção social entre os grupos chaquenhos no século XVIII
}

Messias Moreira Basques Júnior*

Jundiaí, SP: Paco Editorial. 2014. 376p.

O livro A cosmologia construída de fora foi originalmente escrito como tese de doutorado e recebeu o Prêmio Capes na área de História em 2014. Trata-se de uma importante contribuição à história e à etnologia indígena das Terras Baixas da América do Sul, pois se baseia em uma aproximação bem-sucedida entre pesquisas antropológicas e um extenso corpo documental referente às práticas e concepções de povos chaquenhos e às suas relações com o outro no século XVIII: afins e inimigos, missionários e invasores europeus. O livro tem o mérito de abordar uma região pouco estudada pela antropologia brasileira: o Grande Chaco, uma das principais regiões geográficas da América do Sul e que constitui zona de transição entre a planície da bacia amazônica, a planície argentina e a zona subandina. ${ }^{2} \mathrm{~A}$ análise de registros produzidos por observadores civis e religiosos ao longo do século XVIII evidencia o contraste entre o discurso europeu, centrado na denúncia da barbárie e da inconstância que caracterizariam os nativos, e o modo propriamente indígena de responder ao avanço colonial. Felippe examina três aspectos da cosmologia chaquenha: a guerra, a reciprocidade, e o regime de produção e consumo alimentar. O fio condutor da análise é a mitologia desses povos, aqui entendida como fonte de conhecimento sobre o pensamento ameríndio.

Desde o título até suas páginas finais, o livro demonstra a fertilidade da proposição levistraussiana a respeito da importância da "abertura ao outro" no pensamento ameríndio e nos modos pelos quais esses povos costumam se situar diante da alteridade. Segundo Anne-Christine Taylor (2011), essa característica foi desde cedo detectada por Claude Lévi-Strauss, como mostram os dois artigos por ele publicados no ano de 1943 e que estabeleciam "o aspecto

\footnotetext{
* Doutorando em Antropologia Social, PPGAS/Museu Nacional/UFRJ. Rio de Janeiro, RJ, Brasil. messias.basques@gmail.com ${ }^{1}$
} 
sociologicamente produtivo da guerra vista como forma de vínculo ... e a primazia da afinidade no universo social dos índios, a primazia da relação com o não-idêntico sobre as ligações de consanguinidade ou, mais exatamente, de identidade" (Taylor, 2011, p.83). O tema da "abertura ao outro" inspirou profundamente os autores mobilizados por Felippe em seu diálogo com a antropologia e, sobretudo, com a etnologia amazonista. Inserindo-se nessa tradição, Felippe apresenta uma descrição histórica e etnográfica que corrobora uma tendência recente da antropologia chaquenha de acentuar as ressonâncias entre os povos da região e aqueles da Amazônia. Retomando o clássico artigo de Seeger et al. (1979), alguns autores têm defendido a existência de um "pacote amazônico" (Londoño Sulkin, 2012, p.10) cujos componentes também estariam presentes no Grande Chaco e dentre os quais se destacam: o foco no corpo humano e seus elementos como matriz primária de significado social e a existência de um cosmos perspectivista que se encontraria mediado por relações com alteridades perigosas e potencialmente fecundas (Echeverri, 2013, p.41).

O primeiro capítulo trata dos mitos indígenas como construção da realidade, partindo de uma reflexão teórica acerca das diferenças entre o conhecimento objetivo e subjetivo, bem como das concepções de natureza e cultura que fundamentavam o cotidiano e os conhecimentos dos povos chaquenhos no século XVIII. Apesar da grande variedade de versões registradas nas fontes documentais, pode-se notar que, quando tomadas em conjunto, as narrativas míticas refletem problemas similares, como o tema da origem da humanidade e dos animais a partir de uma mesma constituição ontológica, de um fundo comum marcado pela comunicação interespecífica e pela partilha de subjetividade e da capacidade de agência. Felippe descreve como a absorção de elementos exógenos era o eixo do pensamento indígena e, nesse sentido, as transformações criativas que se podem observar na mitologia desses povos revelariam a sua forma de refletir e de responder aos "brancos", ora incorporando, ora recusando elementos do cristianismo, bem como os objetos, animais, atividades e tecnologias trazidos pelos europeus.

No segundo capítulo, a guerra aparece como meio por excelência para a internalização do outro e como produtora de relações entre diferentes sociedades e no interior de cada uma delas. Nas palavras do autor, a guerra chaquenha era diametralmente oposta à guerra praticada pelos europeus, pois "não se fundamentava na extinção do inimigo, nem na busca pela paz. Era, em realidade, o método mais eficaz de estabelecer relações e, consequentemente, movimentar o meio social" (Felippe, 2014, p.121). O modelo utilizado na análise da guerra chaquenha é "amazônico" e se apoia nas teorias da "economia 
simbólica da alteridade" (Viveiros de Castro, 1993) e da "predação familiarizante" (Fausto, 1997). A hipótese, em suma, é a de que em ambas as regiões encontraríamos "economias que predam e se apropriam de algo fora dos limites do grupo para produzir pessoas dentro dele" (Fausto, 1999, p.266-267).

Esse capítulo oferece um sólido contraponto às teses que defendem a ocorrência de escravidão - e o uso desse conceito na análise das práticas de apresamento - entre os ameríndios (cf. Santos-Granero, 2009), pois Felippe demonstra que "ao grupo vencedor interessava capturar pessoas e levá-las à sua aldeia como cativos de guerra, porém sem a intenção de mantê-los prisioneiros ou fazer deles escravos" (2014, p.175). Isto é, os cativos de guerra não eram convertidos em mercadorias e não viviam sob a lógica de uma objetificação de caráter utilitário: "se havia algum acúmulo era de relações sociais, e não de bens" (p.213). O mesmo pode ser dito acerca dos frequentes roubos e assaltos entre os povos da região e, sobretudo, contra reduções jesuíticas, cidades e vilarejos, práticas estas que lhes permitiam a obtenção de montaria, de armas e de bebidas alcoólicas, e que serviriam para intensificar uma lógica preexistente de captura do outro. Em suma, as reduções e as rotas de comércio "proporcionaram aos índios vantagens materiais e estratégicas que acrescentavam elementos à dinâmica relacional nativa - ao invés de substituí-la" (p.141).

A economia indígena é o tema da última parte do livro. No terceiro capítulo, retrata-se o avanço colonial por meio da implantação de relações comerciais e da integração dos povos nativos ao sistema mercantil. Sem menosprezar a violência e as suas consequências, o autor argumenta que os chaquenhos não foram meramente integrados ao mercantilismo, já que são abundantes os relatos acerca do protagonismo indígena no que concerne à potencialização das relações de reciprocidade com outros povos por intermédio de sua participação no comércio e na circulação de mercadorias não indígenas. Não obstante os esforços dos jesuítas para incutir entre os indígenas o sentido da falta e o desejo pela produção de excedentes, Felippe nos mostra que os missionários repetidamente testemunharam o fracasso dessa "conversão" para uma economia de acumulação. Segundo o autor, os Jesuítas não mediram esforços para "introduzir nos índios a insegurança que os modernos tinham em relação ao futuro" (Felippe, 2014, p.305-306). No entanto, se a inconstância era a resposta indígena diante da obrigatoriedade da crença, a prodigalidade parece ter sido a sua contrapartida às ideias de contrato e previdência.

O quarto capítulo apresenta as razões de outra recusa: a não incorporação de métodos e técnicas do sistema econômico moderno, em especial, da agricultura como forma de produção de excedente e da domesticação de animais 
para reprodução. Inspirando-se em Sahlins (1994, p.163), Felippe procura demonstrar que as razões dessa recusa não se resumiam a uma divergência de percepções ou aos limites do entendimento dos povos nativos, conforme alegavam os missionários e agentes burocráticos ou coloniais, pois "o problema não era empírico, nem tampouco prático: era cosmológico”. Daí os índios que optaram por ou foram cooptados a viver nos povoados missioneiros não terem se dedicado à domesticação de animais, tampouco demonstrado interesse pela manutenção do "stock de subsistência" oferecido nas haciendas. A recusa à domesticação seria, desse modo, o "efeito de uma impossibilidade", pois "tudo se passa como se entre o amansamento dos animais autóctones passíveis de ser caçados e sua domesticação verdadeira havia um passo que os ameríndios sempre se recusaram a dar" (Descola, 2002, p.103, 107). A resiliência indígena frustrava os missionários, que denunciavam o fato de consumirem "com desordem o rebanho destinado a sua manutenção" (Fernández, 1779 apud Felippe, 2014, p.315) e de sua economia de produção alimentar se limitar ao consumo imediato, mesmo nos casos de povos horticultores.

A invasão europeia no Chaco e o avanço da empresa colonizadora provocaram grande movimentação de povos indígenas, bem como o seu decréscimo populacional e o extermínio de tribos marginais à área chaquenha. Diante das transformações por que passaram, não podemos negligenciar a distância que se impõe entre os modos de vida indígena pré e pós-conquista. Entretanto, há um inegável "ar de familiaridade" (Fausto, 1992, p.381) entre os relatos sobre os chaquenhos dos Setecentos analisados por Guilherme Galhegos Felippe e os povos que hoje se encontram nessa região, o que torna o seu livro leitura obrigatória para antropólogos e historiadores interessados no Grande Chaco e em suas ressonâncias com a história e a cultura dos povos indígenas das Terras Baixas da América do Sul.

\section{REFERÊNCIAS}

DESCOLA, Philippe. Genealogia dos objetos e antropologia da objetivação. Horizontes Antropológicos, v.8, n.18, p.93-112, 2002.

ECHEVERRI, Juan Álvaro. La etnografía del Gran Chaco es amazónica, In: TOLA, F. et al. Gran Chaco. Ontologías, poder, afectividad. Buenos Aires: Asociación Civil Rumbo Sur, 2013, p.41-43.

FAUSTO, Carlos. A dialética da predação e da familiarização entre os Parakanã da Amazônia oriental: por uma teoria da guerra ameríndia. Tese (Doutorado) 
- PPGAS-Museu Nacional, Universidade Federal do Rio de Janeiro (UFRJ). Rio de Janeiro, 1997.

FAUSTO, Carlos. Fragmentos de História e Cultura Tupinambá: da etnologia como instrumento crítico de conhecimento etno-histórico. In: CUNHA, Manuela Carneiro da (Org.) História dos Índios no Brasil. São Paulo: Companhia das Letras, 1992. p.381-396.

. Da inimizade: forma e simbolismo da guerra indígena. In: NOVAES, Adauto (Ed.) A outra margem do Ocidente. São Paulo: Companhia das Letras, 1999. p.251-282.

LONDOÑO SULKIN, Carlos David. People of Substance: An Ethnography of Morality in the Colombian Amazon. Toronto: University of Toronto Press, 2012.

MITCHELL, Peter. Horse nations: The Worldwide Impact of the Horse on Indigenous Societies Post-1492. Oxford: Oxford University Press, 2015.

SAHLINS, Marshall. Ilhas de História. Rio de Janeiro: Jorge Zahar, 1994.

SANTOS-GRANERO, Fernando. Vital Enemies: Slavery, Predation and the Amerindian Political Economy of Life. Austin: University of Texas Press, 2009.

SEEGER, Anthony; DA MATTA, Roberto; VIVEIROS DE CASTRO, Eduardo. A construção da pessoa nas sociedades indígenas brasileiras. Boletim do Museu Nacional, Rio de Janeiro, n.32, p.2-19, 1979.

TAYLOR, Anne-Christine. Dom Quixote na América: Claude Lévi-Strauss e a antropologia americanista. Sociologia \& Antropologia, v.1, n.2, p.77-90, 2011.

VIVEIROS DE CASTRO, Eduardo. Alguns Aspectos da Afinidade no Dravidianato Amazônico. In: .; CUNHA, Manuela C. da (Org.) Amazônia: Etnologia e História Indígena. São Paulo: NHII/USP-Fapesp. p.149-210, 1993.

\section{NOTAS}

${ }^{1}$ Pesquisador do Laboratório de Antropologia da Arte, Ritual e Memória - LARMe/Museu Nacional, Rio de Janeiro, RJ.

${ }^{2}$ A palavra "chaco" deriva do Quechua e significa "grande território de caça" (MITCHELL, 2015, p.15).

Resenha recebida em 14 de dezembro de 2015. Aprovada em 23 de dezembro de 2015. 